\title{
Competition effects in EU external aid supply tenders funded with the Pre-accession and Neighbourhood instruments
}

\section{Luis Mario García Lafuente ${ }^{1}$ (D) Asunción Mochón Sáez ${ }^{2}$}

Accepted: 13 July 2021 / Published online: 12 August 2021

(C) The Author(s) 2021, corrected publication 2021

\begin{abstract}
This paper investigates empirically the competition effects on procurement costs for Europe Aid funded supply tenders in countries benefiting from the EU Pre-accession (IPA) and Neighbourhood (ENI) financial instruments. We use a dataset created and curated by us from supply tender dossiers published by Europe Aid. We determine a reference price for each procured lot based on the contracting authority's requirement to establish a participation tender guarantee. We estimate controlling for potential endogeneity how the entry of new bidders in the tendering procedure affects procurement cost savings regarding this reference price. Finally, we discuss the expected additional savings in the management of these funds that may be obtained by further promoting competition.
\end{abstract}

Keywords Procurement auction · Competition effects · Price signaling · Official development assistance

JEL Classification D44 · D82 · F35 · H57

Responsible Editor: Fritz Breuss.

We want to thank one anonymous referee for the useful remarks and comments.

Luis Mario García Lafuente

mario.garcia@atiex.net

Asunción Mochón Sáez

amochon@cee.uned.es

1 Department of Applied Economics and History of Economics, UNED, Paseo Senda del Rey, 28040 Madrid, Spain

2 Department of Applied Economics and History of Economics,UNED, Madrid, Spain 


\section{Introduction}

Procurement auction is a widespread mechanism for the allocation of public markets with a high relevance in international trade. In particular, procurement auction is the dominant mechanism used in the management of official development assistance (ODA). The volume of ODA funds provided to developing countries by OECD members of the Development Assistance Committee exceeded USD 150 billion in 2019 (OECD 2020). A significant part of these funds comes from European Union institutions. The external action of the European Union funded through Europe Aid Pre-accession instrument (IPA) and Neighbourhood, Development and International Cooperation instrument (NDICI) is expected to reach an allocation over EUR 100 billion in the period 2021-2027 according to the current European Commission Proposal (EC 2020a), (EC 2020b), with a significant increase regarding the budget for the 2014-2020 budgetary period.

Despite this economic relevance, and the instrumental value of these funds for local business development and governance improvement, the number of empirical studies carried out to estimate the cost of the goods and services provided by ODA to the beneficiary countries is very limited. The most frequent argument in the literature is the lack of public data on bidding procedures in development countries. Other authors quote arguments that may be connected to the sensitive political aspects of ODA, (Iimi 2006). Limited data and political implications of EU funding are considered as well in the methodological approach and the context of other empirical studies conducted in countries covered in our work, for instance (Tsanana and Katrakilidis 2014) researching on income convergence with EU.

The purpose of this paper is to measure the effect of competition on procurement costs in a multilateral market of different goods. These goods are supplied to different beneficiary countries from Europe Aid Pre-accession and Neighbourhood funds after following a tender procedure. The goods that are most frequently procured are technological equipment and machinery for different industries. In addition to the added value of these goods for the development of the beneficiary countries, acquiring them at a competitive price contributes to optimize the deployment of their resources and to achieve an efficient use of the funds allocated by the European donors.

We consider that Europe Aid supply tenders are a type of reverse auctions. The contracting authority (the buyer, henceforth) demands openly a product. A set of bidders present their bids according to their bidding strategies and the winning bidder sells the product to the buyer.

In this auction environment, the buyer requires often a participation guarantee to enter the procurement procedure. The guarantee amount provides a signal on the reference price of the tendered product. We estimate a procurement cost savings rate based on this reference price.

We study three statistically consistent empirical models used dominantly in public procurement auction literature. All our models converge significantly in a range that includes the average number of bidders in our sample. Hence, we estimate 
Europe Aid supply procurement cost average savings with robustness. These average savings are modest. Subsequently, we estimate savings potential improvement by further stimulating competition. We find additional savings rates of 7 to 10 percentage points regarding the reference price when the number of bidders increases up to the critical value bounding the relevant convergence region.

Our empirical results are compatible with results of previous works in this field. We present a comparative discussion on these previous results.

We use a dataset with information on all Europe Aid supply tenders called for in the period extending from 2014 to 2017 . The sample consists of independent records curated by us and looked up from the official tendering resolutions published by Europe Aid. These data are not included in any existing database to our knowledge. The data available does not allow to verify the contractor's performance. Hence, our conclusions relate to the allocation of the tendered goods only.

The rest of the article is structured as follows: Sect. 2 provides an overview of the procurement procedure and details of the data used in the research; Sect. 3 explains the estimated regression models; Sect. 4 shows the results of the empirical analysis and discusses comparatively their interpretation; and Sect. 5 draws the conclusions.

\section{Overview of the procurement procedure and the data used in the research}

International development assistance tenders may be classified depending on the number of bidders that are admitted to participate in the tender procedure called by the contracting authority. A basic and comprehensive typology is the following:

\footnotetext{
Open procedure : Any bidder may submit a bid.

The bidder must provide evidences of technical and economic capacity.
}

Restricted procedure : Only a maximum number of $n$ bidders may submit their bids.

The contracting authority selects the qualified bidders after conducting a prequalification procedure with criteria of capacity.

Negotiated procedure : Only a reduced number of $n^{\prime}$ bidders may submit their bids.

They are invited at discretionary criteria by the contracting authority.

For instance, after successful implementation of a previous contract.

In addition, based on the goods that are being tendered, tenders are usually classified in three broad categories: works, supplies and services. Generally, Europe Aid tenders for works and supplies use open procedures, while tenders for services use restricted procedures. ${ }^{1}$

\footnotetext{
${ }^{1}$ Tenders for services, apart from the bid, include an additional technical component influencing the score of the resolution. This means that the quality of the technical component is assessed in conjunction with the bid. Tender assessment costs to be incurred by contracting authority influence the maximum number of admitted bids.
} 
Europe Aid uses negotiated procedures in limited cases. They usually apply to small-amount contracts or under exceptional situations. They also apply when a previous procedure (open or restricted) has been unsuccessful, but the detected faults may be amended. In this last case, the contracting authority must motivate the decision based on technical and efficiency criteria against the alternative of relaunching the tender procedure.

Besides the descriptive purpose, this basic classification is relevant for the choice of the sample in our study. The principle of identically distributed observations in the empirical estimation of the models may not be reasonably met for a sample that mixes procurement procedures with different restrictions on the number of admitted bidders, especially when the number of incumbent bidders is high.

In this paper we use a sample of supply tenders only. For every tender procedure $n$ bidders bid openly in a procurement auction, $n$ being unknown before the resolution of the auction. Tenders are open to international competition and bidders must respect the general rules of participation established by Europe Aid. ${ }^{2}$ We assume that the number of bidders is an endogenous factor a priori of the auction procedure.

Bidders submit their bids in a sealed envelope. To be eligible for each specific tender, bidders must also provide several documents proving their technical and financial capacity. ${ }^{3}$ In addition, the contracting authority usually requires the bidders to provide a tender guarantee to participate in the auction with the purpose to deter them from leaving the procedure. The amount of the tender guarantee fixed by the contracting authority after a compulsory market study operates as an entry cost to the auction procedure. This amount also provides information about the engineered (or reference) market price of the tendered lot and about the contracting authority's reserve price, that is, the maximum price that she can pay with the funds that Europe Aid has allocated to the tender.

The auction procedure follows a first-price rule. The bidder with the lowest bid becomes the winner. The amount the winner receives matches the price of her bid. The bidders cannot modify their bids during the auction. Once the bid with the lowest price has been determined, the winner may be required to provide new documentation to confirm her capacity before signing the contract at the bidding price. The contract signed by the contracting authority and the winner terminates the auction procedure and the awarded price is officially published.

We identify the awarded price of the auction with the procurement cost and we define it as follows. ${ }^{4}$

$$
P^{*}=\min \left\{B_{j}\right\} \quad j=1 \ldots n
$$

\footnotetext{
${ }^{2}$ Bidders' nationality, origin of the goods and not falling within any legal and administrative exclusion criteria. Nationality and origin rules include, in general, EU and European Economic Area member states, and Europe Aid beneficiary countries.

${ }^{3}$ Usually, these are evidences of successful sales of similar goods and the description (or confirmation) of the features of the offered product.

4 We may think of other costs associated to the tender procedure, but the homogeneity of the procedure in the selected sample makes reasonable assuming that these other costs are similar in all cases, and therefore the relevant cost is the price of the acquired lot.
} 
Where $B_{j}$ is the bid of the $j$ bidder in the group of $n$ competing bidders and $P^{*}$ is the awarded price.

\subsection{Data overview}

The empirical analysis is based on a dataset extracted from the publications issued by Europe Aid. ${ }^{5}$ We curated the data by looking up and classifying all the relevant information for our research. The sample in our dataset includes data from 220 tender dossiers for supplies of different goods called in different beneficiary countries.

The majority of the procured goods are equipment and machinery for different industries (around 35\% of the total). Hardware and Software is also a dominant category of goods in our sample (around $29 \%$ of the total). The rest of the goods are different kind of vehicles, medical and chemical materials, and furniture.

The tender dossiers include one or several lots. In general, the lots are awarded simultaneously. Every lot produces an independent observation coming from an independent auction procedure, because it corresponds to a specific indivisible product and it has an independent awarded price.

The sample includes all the tenders called for between 2014 and 2017, and funded with the financial instruments of: Neighbourhood (ENI), with supply procedures in Morocco, Egypt, Tunisia, Jordan, Lebanon and Algeria; and EU Pre-accession (IPA), with supply procedures in Albania, Bosnia, FYROM (Former Yugoslav Republic of Macedonia, currently North Macedonia ${ }^{6}$ ), Serbia, Montenegro and Turkey. In addition, we include Kosovo under the status of the resolution of the United Nations Security Council $1244^{7}$ as a singular geographic market, owing to the fact that Kosovo benefited both from IPA funds and funds from the instrument EULEX.

Some of the lots are awarded after several months from the initial call for tender and the publication of the official resolution takes some time as well. Hence, we have chosen the date of 31/05/2018 as the deadline to collect data from Europe Aid published dossiers. ${ }^{8}$

The data extraction rule yields all the subsequent tenders in a limited period in order to obtain a statistically representative number of observations for the empirical analysis. This methodology is used in similar empirical studies, such as (Iimi 2006) and (Onur and Özcam 2012).

\footnotetext{
${ }^{5}$ The publications can be accessed through this website: https://ec.europa.eu/europeaid/home_en

${ }^{6}$ We use the acronym FYROM in the body of the paper to be consistent with the denomination existing in the data collection period.

${ }^{7}$ In this paper, any mention to Kosovo must be understood in connection with the referred United Nations status.

${ }^{8}$ This deadline has been taken considering the average period of 7-8 months for the entire procedure estimated in Europe Aid regulations. The tender publication date of the last record in our sample corresponds to September 2017.
} 


\subsection{Characterization and treatment of the data}

In our sample there are 479 awarded lots with a specific price that is public and 108 unsuccessful procedures. The unsuccessful procedures yielded void lots and they resulted in one of the following situations: relaunching of a new tender procedure or cancellation of the tendered lot.

Among the awarded lots, 29 correspond to negotiated procedures. All the negotiated procedures arise from an unsuccessful previous open procedure. ${ }^{9}$ Thus, the negotiated awarded price behaves in a similar way than the price awarded in open procedures because it must fulfill the same restrictions.

Several unsuccessful tendered lots have originated relaunched procedures within the period covered by our sample. In these cases, the dataset includes two different records: the first one includes the unsuccessful initial lot (a record with no bids). The second record includes the data of the awarded relaunched lot. ${ }^{10}$ When the procedure is unsuccessful and the lot is canceled the sample includes only one record with no bids.

The buyer generally breaks down the number of received bids per lot in the resolution of every tender. There is a reduced number of 25 tenders in which the number of bidders included in the resolution is the global number of bidders for all the tendered lots. In the estimation of the empirical models we discard those records where we cannot ascertain the real number of bidders competing for the single lots.

The buyer decides to take a joint resolution for several lots very seldom. In these cases, she issues a single contract to the winner for the total awarded price of the several lots involved and creates a composite lot ad hoc. In these cases, there is only one observation recorded in our dataset. The record registers the awarded price for the composite lot and the sum of the amounts of the tender guarantees required initially to bid for the original lots.

\subsubsection{Reference price signaling}

Our dataset includes 457 lots in which the buyer required a tender guarantee to enter the procurement auction and 130 in which such a guarantee was not required. The rules of the tender procedure (DEVCO 2018) establish that the contracting authority is entitled not to require the participation tender guarantee to the bidders for proportionality reasons. This happens when the reserve price is below a certain threshold, although many contracting authorities prefer to require the participation tender guarantee also in those cases.

\footnotetext{
${ }^{9}$ In the initial open procedure all prices may have exceeded the contracting authority's reserve price, although some could be close to it and the related bidders may be invited to reconsider them with a new bid. Or the contracting authority may consider that some faulty technical aspects can be amended upon her request, while holding the received bids.

10 The lot that is tendered in the relaunched procedure may change its specifications. For instance, the quantities of the goods, their features or the amount for required tender guarantee may vary. Therefore, we consider that it is reasonable to keep two separated records in the sample because they are strictly different procurement auctions.
} 
The buyer' reserve price, $P_{R}$, is private. The bidders do not know the exact amount over which the buyer will not acquire the lot. However, the rules of the tendering procedure (DEVCO 2018) establish that the tender guarantee must fall between $1 \%$ and $2 \%$ of the engineered (or reference) value of the contract. Therefore, we can infer the buyer's reference price, $P_{r e f}$, from the price signal of the tender guarantee. This reference price is known by all the bidders and may be interpreted as an indicator of the common value for the lot, if this exists. We calculate the reference price with equation (2).

$$
P_{\text {ref }}=A / 0.015
$$

Where $A$ is the amount of the tender guarantee.

We use the middle point of the interval bounded by the thresholds of the tender guarantee amount to calculate the reference price of the lot for symmetry reasons ${ }^{11}$. This variable is well-defined in economic terms and it allows a robust and conservative estimation of the procurement cost savings. Comparing the awarded price to the unknown reserve price of the lot yields higher estimated savings, because the following inequality holds in all cases: $P_{R}>P_{\text {ref }}$.

Under the assumptions that the preliminary buyer's market study for the tendered lot provides always a precise and accurate value and that the buyer is risk neutral ${ }^{12}$, the highest threshold signaled by the tender guarantee provides a bound to the buyer's reserve price: $P_{R} \geq A / 0.010$. This bound is useful to estimate the maximum savings that may be achieved with the auction mechanism, although they might be affected by an overestimation bias if the mentioned restrictive assumptions are not satisfied.

Table 1 presents a summary of the features of the numeric variables explained in this section for those tendered lots awarded with a price $P^{*}$, as defined in equation (1). The variable for the tender guarantee amount is named aval. Finally, the reference price corresponds to the definition in equation (2).

Table 1 shows that we build a reference price for all the tenders with the requirement of a tender guarantee. The number of observations with a defined awarded price $P^{*}$ includes tenders both with and without a participation tender guarantee. Our empirical work uses only those observations for which a reference price exists based on the tender guarantee price signal.

We finish this section with Fig. 1. It presents the distribution of the number of bids per lot, when this number is stated in the official resolution. It includes the tenders where the requirement of a participation tender guarantee has been established

\footnotetext{
11 The choice of this reference price does not imply any interpretative restriction for the results, because the quantitative estimation of costs savings must be related to a reference price. The choice of any other reference price based on the tender guarantee involves an algebraically transformation of the coefficients of the models only.

12 The buyer's strategy is to give a true signal of the lot value with the tender guarantee amount, instead of a signal prioritizing its purchase even if this is produced at a higher cost.
} 
only. The right-skewed shape is similar to the one found in previous studies on this topic. In lighter color we show the unsuccessful tendered lots (void lots with 0 bids) and in darker color than the rest we show the tendered lots that received 10 bids or more $^{13}$. We also depict the mean of the distribution.

It is important to notice that a significant percentage of more than $15 \%$ of the resolutions are void. There are multiple reasons for such unsuccessful tenders, ranging from the early cancellation by the contracting authority to the absence of valid bids.

Milgrom and Weber (1982) study the effects of revealed information in a sealedbid auction. They conclude that this strategy raises competition when the revealed information contains part of the better-informed bidders' information. We find this effect in our work when comparing void tenders in procedures with and without participation guarantee requirement. In this last case the ratio of void tenders raises to more than $35 \%$.

Unsuccessful auction procedures entail additional procurement costs, whether they involve relaunching or cancellation of the tendered lots. These costs are not accounted for in our work, but the incorporation of these unsuccessful cases to calculate the mean of the bids in our sample allows to estimate more accurately the expected additional savings with increased competition.

\section{Models}

In our models, we consider a random number of $n$ bidders entering each tendering procedure. The tenders include different products and different countries. We control for this heterogeneity with the variables described in Sect. 3.1.

Each bidder estimates a cost for the tendered lot and defines her bidding strategy based on it. The estimation of this cost may come from a value of the cost that is the same for all bidders (Common Value Paradigm, CVP); from a value of the cost that is private for each bidder (Independent Private Value Paradigm, IPVP); or from a value of the cost derived from a broader paradigm (Affiliated Value Paradigm, AVP), where the CPV and the IPVP are the extreme special cases.

We assume that bidders are non-cooperative and they use a benefit optimizing strategy. We also assume market equilibrium, in line with the principles to build structural models. (Paarsch 1992) applies them to build and use structural theoretical models for CVP and IPVP. We do not assume a priori any cost distribution paradigm or specific simplifying assumption to define a closed form. The reason is that the auctions in our study are likely affected by information asymmetry caused by the international origin of the bidders, their different size and the possibility of joint bidding, among other circumstances.

A few empirical studies characterizing bidders' asymmetries exist in the literature. (Bajari 2001) for highway construction and (Flambard and Perrigne 2006) for snow removal auctions analyze asymmetries based on bidders' geographic locations.

\footnotetext{
13 The tenders with 10 bids or more have been grouped in a single category in some of our empirical models to achieve statistical representativeness.
} 
Table 1 Features of the main numeric variables for all the awarded lots (in EUR)

\begin{tabular}{lllllllll}
\hline Variable & N & Mean & St. Dev. & Min & \%ile(25) & Median & \%ile(75) & Max \\
\hline Aval & 457 & 9597 & 37,679 & 100 & 1500 & 3050 & 7000 & 600,000 \\
Pref & 457 & 639,789 & $2,511,948$ & 6,667 & 100,000 & 203,333 & 466,667 & $40,000,000$ \\
P* & 479 & 539,160 & $2,135,949$ & 580 & 53,480 & 169,770 & 391,375 & $29,676,883$ \\
\hline
\end{tabular}

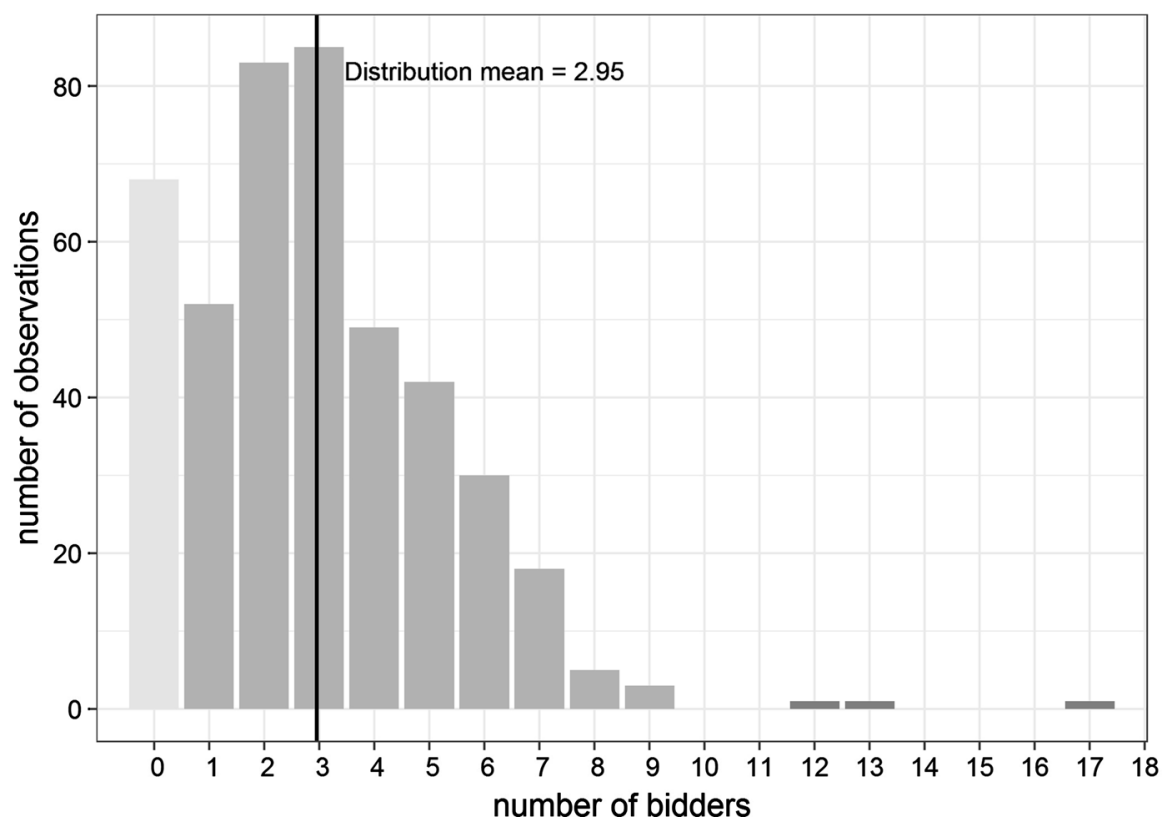

Fig. 1 Distribution of number of bidders for tenders with requirement of a participation tender guarantee

(Hendricks and Porter 1992) discuss asymmetries associated to joint bidding for oil lease auctions. (Armantier and Sbaï 2006) find asymmetries based on bidders' capacity to obtain quality information and on risk aversion for French Treasury auctions.

Auctions with information asymmetry result in non-closed form solutions to the equations characterizing the bidding equilibrium strategies in general situations like ours (Campo 2003). Simplified models require restrictive assumptions and the full set of bids.

In our research, we consider initially a non-closed relationship between procurement costs and number of bidders. As the tenders involve a restricted number of bidders, we can apply an empirical discrete model to treat flexibly this situation. Furthermore, if we assume that the real features of our auction environment approximate to conditions for a closed form, we would expect it to be non-linear.

Hence, our empirical approach is to test several discrete models and closed nonlinear functional forms regressing the procurement cost on the number of bidders, 
controlling for heterogeneity market factors. We then select those which are statically consistent and compare their results.

We describe our models in Sects 3.2 and 3.3, and we provide references of auction environments where they have been previously used.

With this approach, our results are valid in an unchanged empirical framework in which our estimated models are consistent (Rezende 2008). The stable framework of Europe Aid financial instruments along the years and the similar operation of other ODA funding institutions make reasonable the comparison of our conclusions with results in broader similar auction environments.

\subsection{Description of main variables}

The dependent variable of the models is a composite variable, which is strictly associated to the awarded lots. We define it as follows:

- Normalized procurement cost. This variable is named indpago in the models and represents the ratio between the awarded price of the lot, or procurement cost $P^{*}$ as defined in (1), and the reference price, Pref, as defined in (2).

$$
\text { indpago }_{k}=P_{k}^{*} / \text { Pref }_{k} \quad k=1,2, \ldots, K
$$

where $k$ represents each of the $K$ awarded lots included in the sample that required the provision of a tender guarantee to participate in the tender.

This choice of the dependent variable is useful to interpret directly the marginal effects of competition on the procurement cost, controlling for other specific auction attributes in the procedure that are statistically significant. The lacking information on the bidders' characteristics in our sample is partially captured by the market study yielding the reference price. A consequence of this lacking information is the potential endogeneity of the number of bidders in the empirical models.

There is a strong correlation between the procurement cost and the reference price $^{14}$ of the lots. Referring procurement cost to this engineered price, which is calculated homogeneously across tenders, allows us to isolate the effect of competition based on the accessible data of the winning bid only. It also limits prices intertemporal effects. The few studies on this topic counting with a reference price for the tendered lots make the same treatment for this variable. See for instance, (Onur and Özcam 2012).

Finally, the normalized approach allows to calculate immediately the savings rate, $S R$, which is the main objective of our paper.

$\overline{14}$ The coefficient of determination of the linear regression between both variables is greater than 0.90 . 


$$
S R_{k}=\frac{\operatorname{Pref}_{k}-P_{k}^{*}}{\operatorname{Pref}_{k}}=1-\text { indpago }_{k} \quad k=1,2, \ldots, K
$$

where $\mathrm{k}$ and $\mathrm{K}$ have the same interpretation than in equation (3).

We analyze subsequently the regressors in our models.

- Number of bidders. This is the main regressor. In indicates the level of competition in the procedure. We represent it either as a set of discrete variables or as an approximation to a continuous variable.

When we represent it as a set of discrete variables, we define individual categories with subscripts. For instance, $B I D S_{3}$ is a dummy variable taking the value 1 when the number of bidders participating in the tender is 3 , and the value 0 otherwise. When we represent it as a continuous variable, it is called bids. It takes the value 0 when the procurement auction is unsuccessful and otherwise it takes the value of the number of valid bids received by the contracting authority.

Our empirical methodology considers all the characteristics that the variable representing the number of bidders in the auction may exhibit, taking into consideration:

- its endogenous or exogenous behavior in the model.

- its modeling as a categorical variable (individual non-linear effects) or as a continuous variable in a closed functional form.

In the models where the number of bidders is endogenous, the effect of competition on procurement costs is biased. In addition to control for the heterogeneity of the market, we correct the bias with instrumental methods. When we use the number of bidders as a categorical variable (which is essentially its nature as the number of bidders is an entire number), the empirical models allow the estimation of different effects with every new bidder entering competition. When we use the continuous variable approximation, we obtain a smoother entry effect.

We consider the following regressors to control for the heterogeneity of the market:

- Market place. Data on the market place have been modeled with a set of categories. We created the categories taking into consideration the Europe Aid financial instrument funding the tender and the geographic position of the countries as differentiating factors. We represent the categories in our models with dummies. DCATMARI takes the value 1 for tenders in Turkey, which is the country with the highest number of supply tenders called for. DCATMAR2 takes the value 1 for tenders in those countries benefiting from the IPA instrument, excluding Turkey and Kosovo, which benefit from IPA as well. DCATMAR3 takes the value 1 for tenders in Kosovo, which benefits both from EULEX and IPA instruments. 
The beneficiary countries from ENI, the Neighbourhood instrument, is the base group in our models.

- Product. The tendered products in our sample are heterogeneous. We classify the data in general categories traditionally well recognized by the bidders competing for Europe Aid supply contracts ${ }^{15}$. We represent the categories in our models with dummies. DCATPRO1 takes the value 1 for lots in the general category of furniture. This category includes dominantly pieces of furniture to equip offices and premises of different organizations. DCATPRO2 takes the value 1 for lots in the general category of hardware and software. This category includes computers, peripherals and software applications for different purposes. DCATPRO3 takes the value 1 for lots in the general category of mechanical and industrial equipment and machinery. This category is broad because it encompasses equipment for different industries. DCATPRO4 takes the value 1 for lots in the general category of vehicles. The dominant products in this category are road vehicles like cars, vans and buses. In some cases the contract relates to spare parts. The category medical, forensic and laboratory equipment includes medicines, vaccines, laboratory instruments and materials of chemical nature. We use this category as the base group for products in our models.

Other data have been modeled with dummies. These dummies have been tested in our models without resulting statistically significant. These include a dummy indicating whether the award relates to a negotiated procedure following an unsuccessful open call, a dummy indicating whether the scope of the tender is local ${ }^{16}$ and another dummy indicating whether the tender included one or more lots.

Finally, to test the endogeneity of the variable bids we use instrumental variables. Instruments in our case are difficult to find for three reasons:

- They can be endogenous to the auction procedure as well.

- They may not have enough instrumental value.

- A trustable source of data for the instrumental variable in all the different countries included in our sample may not exist.

We select the following instruments that fulfill the necessary instrumental criteria:

- Gross domestic product lagged one year (GDP_1). GDP characterizes the development of each beneficiary country. Hence, it may reasonably have an influence

\footnotetext{
15 The tender dossiers used as data source include generally several classification codes of the goods for each lot. These codes follow the CPV (Common Procurement Vocabulary) standard. We use in our study a classification in general categories according to these codes and to the description of the goods in the tender dossiers. We select the dominant nature of the lot when goods with several CPV codes are listed in it.

${ }^{16}$ Local tenders are open to international bidders, but they may establish specific rules hampering broader competition like local publicity only, local administrative procedures, quotations and payments in local currency and other restrictions influencing bidders' decision to enter the tender. A tender with local scope involves always a contract value below a certain threshold. In the period covered by our study this threshold is 300.000.- EUR.
} 
on the bidders' decision to tender. Countries with higher GDP may trigger a higher interest in the tender procedure from domestic and foreign bidders. We take the annual GDP in year 2000 constant USD billion.

- DTF lagged one year (DTF_1). The index DTF (Distance to Frontier) captures the gap between the country performance and a measure of the best practice performance across a sample of 41 indicators related to the regulatory economic environment. It does not have necessarily the same behavior than GDP ${ }^{17}$. The economic argument to choose this instrument is similar to the argument for GDP regarding the potential interest of foreign bidders. A better performance in this macroeconomic index may stimulate the participation of foreign bidders.

- Exports to the European Union lagged one year (EXPORTS_1). Exporting figures are an indicator of foreign trade activity of the beneficiary countries and they may have an influence on the number of incumbent bidders for the procured goods in our sample. We consider exports to EU countries to account for the fact that Europe Aid tenders involve mostly ${ }^{18}$ direct trade between EU countries and beneficiary countries.

We build this variable from the data of the Direction of Trade Statistics of the International Monetary Fund ${ }^{19}$. This source presents FOB Exports in current USD million. In order to make the figures retrieved from this source consistent with our previous instruments we convert them to constant USD million ${ }^{20}$.

GDP, DTF and EXPORTS are lagged one year in our models because this is the information accessible to the bidders when tendering.

\subsection{Models assuming discrete and exogenous number of bidders}

Under this non-linear approach of the dependence between procurement cost and number of bidders, we estimate models in which the dependent variable indpago is expressed either in levels or in logarithms.

$$
\begin{gathered}
\text { indpago }=\beta_{0}+\sum_{i=2}^{10} \beta_{i} B I D S_{i}+\lambda x+u \\
\log (\text { indpago })=\beta_{0}^{\prime}+\sum_{i=2}^{10} \beta_{i}^{\prime} B I D S_{i}+\lambda^{\prime} x^{\prime}+u^{\prime}
\end{gathered}
$$

\footnotetext{
17 The source of macroeconomic data for $G D P_{-1}$ y $D T F_{-1}$ is the webpage http://www.doingbusiness.org/ en/methodology of the World Bank, which provides detailed information on the methodology for the elaboration of the mentioned variables.

18 This is due to the rules of nationality and origin.

19 At the webpage https://data.imf.org.

20 To accomplish that we deflate the exports values by using the Consumer Price Index indicator of the World Bank: https://data.worldbank.org. This indicator uses 2010 as the reference year for the index.
} 
$\boldsymbol{x}$ and $\boldsymbol{x}^{\prime}$ represent the different statistically significant variables characterizing the market place, the product and any other relevant variable related to the tender procedure.

This flexible non-linear functional form for the number of bidders is the one suggested when the bidders' value distribution is unknown and the purpose of the study relies on a simplified structural model. (Rezende 2008) proposes it under the assumption of bidders' independent private values. This functional form is also used in the broader context of CVP and AVP. (Brannman 1987) use it to analyze the price-effect of competition for bonds, oil and timber auctions.

The estimation of models (5) and (6) by OLS does not present difficulties and the interpretation is immediate: each coefficient $\beta_{i}$ and $\beta_{i}^{\prime}$ provides information of the entry effects of each new bidder on the procurement costs expressed in levels and as a semi-elasticity, respectively. This price effect of competition is conditioned to the specific market place and product represented by the value taken by the rest of the variables with statistically significant coefficients $\left(\lambda\right.$ and $\left.\lambda^{\prime}\right)$. The main difficulty for the use of these models is to ensure the statistical representativeness of the different categories of the number of bidders, in particular those which are less frequent ${ }^{21}$. We use heteroskedastic consistent estimators to correct for the higher variance associated to those categories.

\subsection{Models assuming number of bidders as potentially endogenous and treating it as a continuous variable}

The models described in this section include the number of bidders, bids, as an approximation to a continuous explanatory variable for all the range of positive values. The dependent variable is the logarithm of indpago. bids enters the models in three different functional forms: quadratic, linear and logarithmic. These variations of the model are the ones included in (Iimi 2006). The three variations provide consistent results with different levels of goodness of fit. Other empirical studies relax even more the potential non-linearity of bids considering a flexible parametric approach to identify the most accurate functional form of bids to be included in the model (Chapela 2019).

The approximation of bids to a continuous variable is useful to overcome the difficulties associated to the reduced representativeness of the higher categories of the number of bidders in the models of Sect. 3.2. In addition, this approximation enables the use of correcting treatments to its potential endogeneity in the estimated models.

We use instrumental variable methods to correct for potential endogeneity. We build a structural equation regressing $\log$ (indpago) on a function of bids and other exogenous variables, and a reduced form that estimates bids with a second regression. Equations (7) and (8) summarize the general form of the instrumental model.

\footnotetext{
21 The empirical application of models (5) and (6) in our work uses a single category for those auction procedures with 10 or more bidders. The information on the base group of procedures with only one bidder is included in the intercept to avoid perfect multicollinearity.
} 


$$
\begin{gathered}
\log (\text { indpago })=G\left(\text { bids }, x_{M}, x_{P}\right)+e \\
\text { bids }=F\left(z_{M}, z_{P}, z_{L}\right)+\epsilon
\end{gathered}
$$

If the variable bids does not exhibit endogeneity, structural equation (7) holds alone as the most efficiently estimated model. If it does, then equation (8) enables the endogeneity correction.

The generic variables $\boldsymbol{x}_{\boldsymbol{M}}$ and $\boldsymbol{x}_{\boldsymbol{P}}$ represent respectively the market place and product variables defined in Sect. 3.1. $z_{M}$ is the set of instrumental variables related with the market places, which must satisfy $\boldsymbol{x}_{M} \subseteq z_{M}$, and in addition they must be valid instruments. In a similar way, $z_{P}$, satisfying $x_{P} \subseteq z_{P}$, is the set of valid instrumental variables related to the products. Finally, $z_{L}$ groups any other exogenous factors to the bidding procedure that satisfy the conditions of valid and relevant instruments.

We use the three instruments described in Sect. 3.1 and two different instrumental variable (IV) estimation methods: 2SLS and GMM, for the generic model defined in this section with linear approximation.

\section{Empirical application. Higher competition reduces procurement cost}

In this section, we apply the models defined in Sect. 3. We compare the models assuming the number of bidders as a categorical variable with those assuming it as a continuous variable expressed in different functional forms. In this last case, we control for endogeneity of this variable in the structural equation (7). At the end of the section we illustrate both approaches with a graphic representation of the procurement costs savings they predict with the entry on new bidders.

\subsection{Models assuming number of bidders as exogenous discrete variable}

Table 2 presents the estimation of the two best-fitting models based on the generic specification in (5) and (6). Both models include as statistically significant variables all the categories representing the number of bidders and the variable, DCATPRO1, which represents the category of furniture goods.

All the coefficients associated to the categories representing the number of bidders include a negative sign. This indicates that competition reduces procurement costs regarding those tenders of the base group. The base group represents procurement auctions with only one bidder for non-furniture goods. The effect of competition is continuously growing up to 6 to 8 bidders. From 9 bidders onwards, the effect of competition becomes stable. Tenders for furniture goods are more competitive than the rest (savings are higher), based on the negative coefficient of the variable DCATPRO1. 
Table 2 Best-fitting estimated models assuming number of bidders as an exogenous and discrete variable

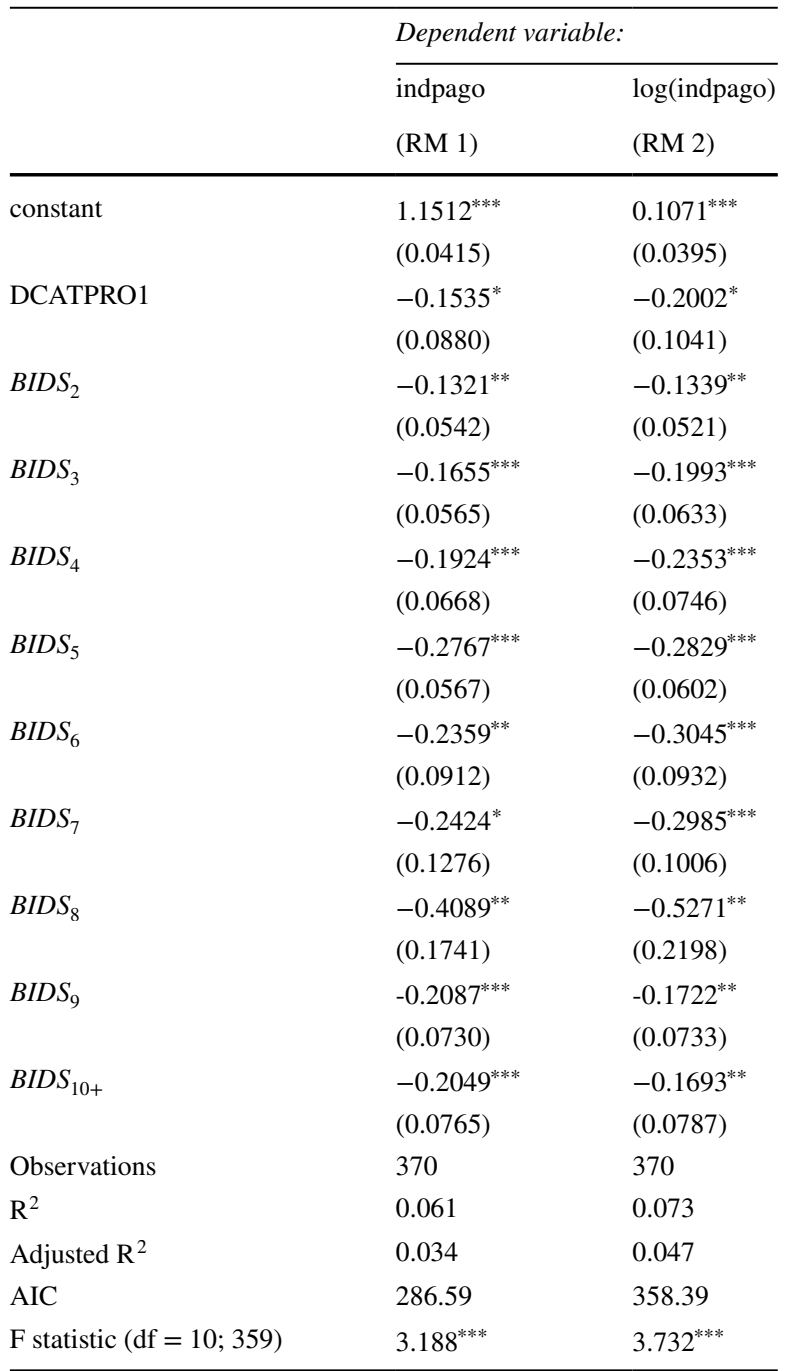

Robust estimations $\mathrm{HCO}$

${ }^{*} \mathrm{p}<0.1 ;{ }^{* *} \mathrm{p}<0.05 ;{ }^{* * *} \mathrm{p}<0.01$

We use Ramsey's RESET test ${ }^{22}$ to detect functional misspecification of any of the models. We obtained a negative result of the tests. Consequently, we cannot reject the null hypothesis that both models are correctly specified at the usual $95 \%$ confidence level.

\footnotetext{
${ }^{22}$ We take the usual variant of including the squared and cubed terms of the independent variable fitted values in the expanded regression.
} 
Table 3 Best-fitting models assuming number of bidders as an exogenous and continuous variable in different functional forms

\begin{tabular}{|c|c|c|c|}
\hline & \multicolumn{3}{|c|}{ Dependent Variable: } \\
\hline & \multicolumn{3}{|l|}{$\log ($ indpago $)$} \\
\hline & (RM3v1) & (RM3v2) & (RM3v3) \\
\hline DCATPRO1 & $\begin{array}{l}-0.1595 \\
(0.1050)\end{array}$ & $\begin{array}{l}-0.1721^{*} \\
(0.1046)\end{array}$ & $\begin{array}{l}-0.1635 \\
(0.1038)\end{array}$ \\
\hline bids & $\begin{array}{l}-0.0370^{* * * *} \\
(0.0095)\end{array}$ & $\begin{array}{l}-0.0271^{* * *} \\
(0.0052)\end{array}$ & \\
\hline$b i d s^{2}$ & $\begin{array}{l}0.0016 \\
(0.0011)\end{array}$ & & \\
\hline $\log ($ bids $)$ & & & $\begin{array}{l}-0.0950^{* * *} \\
(0.0171)\end{array}$ \\
\hline Observations & 370 & 370 & 370 \\
\hline $\mathrm{R}^{2}$ & 0.094 & 0.091 & 0.100 \\
\hline Adjusted $\mathrm{R}^{2}$ & 0.086 & 0.086 & 0.096 \\
\hline AIC & 353.27 & 352.44 & 348.46 \\
\hline F statistic & $11.51^{* * *}(3 ; 367)$ & $16.08^{* * *}(2 ; 368)$ & $18.16^{* * *}(2 ; 368)$ \\
\hline
\end{tabular}

Note: Robust estimations HC0

${ }^{*} \mathrm{p}<0.1 ;{ }^{* *} \mathrm{p}<0.05 ;{ }^{* * *} \mathrm{p}<0.01$

Because the dependent variable is different in the models, we make additional calculations to determine which functional form is preferred. The method can be found in (Wooldridge 2012). We select functional form (5) expressing the normalized procurement cost in levels as the best-fitting one to our empirical data.

Finally, we conduct an outlier test based on the concepts of leverage and influence used in (Davidson and MacKinnon 2003). We detect two potential outliers in the observations of the sample. Both relate to auctions with a significantly high number of bidders and an unusual procurement cost. We have kept both observations in the estimation of our models because we did not find evidence of their influence in the regression beyond the limits usually established. None of the cases shows any remarkable inconsistency in the auction procedure based on the public information found in the tender dossier.

\subsection{Models assuming number of bidders as a potential endogenous variable and treating it as continuous}

As a preliminary step, we estimate the structural equation of the general model represented by equation (7). We consider all the regressors associated to the tendering procedure. We fit the subsequent nested models until reaching the best-fitting one according to the higher adjusted $R^{2}$ and lower AIC criteria.

In these models, we use bids in the three functional forms indicated in Sect. 3.3: quadratic, linear and logarithmic. 
Table 3 presents the estimation of these models with heteroskedastic consistent standard errors.

The regressions of the three variants of the structural equation (7) produce estimations that are consistent with the results of the models estimated in Sect. 4.1. Their coefficients indicate a reduction of the procurement cost as the number of bidders increases. Only the product category related to furniture goods exhibits a behavior different from the rest. Even when the coefficient is not significant at the usual level of $95 \%$ confidence, its inclusion improves the fitting of the three models and it affects the value of the coefficients related with the variable bids.

The model including the quadratic form of bids does not improve the model in which bids appears in linear form only. Its adjusted $R^{2}$ is similar, its AIC statistic is higher and the Ramsey's RESET test gives a p-value just above the threshold of adequate functional specification at the $95 \%$ of confidence. In addition, the coefficient of the quadratic form is not statistically significant.

According to the adjusted $R^{2}$ and AIC criteria, the third functional form with the variable bids in logarithmic form is the empirically best-fitting model.

The reduced form (8) of the IV model enables testing for potential endogeneity of the variable bids.

Endogeneity tests are found in the few works following a similar approach to ours, for instance (Onur and Özcam 2012). In economic terms, sources of endogeneity may be associated to features of the auction environment not captured in our models. They affect procurement costs and, in addition, amplify or reduce the effect attributed to the number of bidders. Categories of products and market places are already included in our models, but there might be other missing specificities related to them. Furthermore, bidders' characteristics in each tender are absent from the available public data and, hence, excluded. Finally, there are different contracting authorities involved. Even when the general procedure is the same for all of them, there may be distinguishing management patterns in the individual beneficiary countries not captured in our models.

A first indication of the potential endogeneity of the variable bids in the structural equation can be obtained from the correlation between this variable (in the functional form entering the model) and the residuals of the corresponding estimated model in Table 3.

For the model with bids in linear form, this correlation yields the following value: corr $=-0.0543$, with $p$-value $=0.2975$. Therefore, we cannot reject the hypothesis that the correlation is not significantly different from 0 at the usual $95 \%$ of confidence and, thus, there is no clear evidence of endogeneity of bids in this model.

However, for the model with bids in logarithmic form, this indicator points at certain level of endogeneity. The correlation value is: corr $=-0.0925$, with $p-$ value $=0.0755$. Therefore, correlation would be reduced, but significant at the 92.45\% level of confidence.

Economic reasons and this first indicator of endogeneity justify that we test for potential endogeneity of the functional form of bids in the estimated models. 


\subsubsection{Estimation of the structural model with IV methods}

Both GDP_l and EXPORTS_l fulfill the initial conditions of adequate instruments for the variable bids, because at the usual level of confidence they have a significant correlation with this variable (relevance condition) and an insignificant correlation with the residuals (exogeneity condition) of the models estimated according to the structural equation (7). DTF_l presents a reduced correlation with the variable bids, and no correlation with the residuals of the concerned models. Therefore, we can use it in conjunction with GDP_l and EXPORTS_l if it proves to increase the joint instrumental power.

Exports are a component of GDP through the balance of trade and they may be correlated. Hence, it is advisable not to include both instruments in the same model. However, replacing one instrument with the other in our models provides a test of robustness for the coefficient of our instrumented variable.

We estimate again models RM3v2 y RM3v3 in Table 3 controlling for endogeneity. First, we use the instruments $G D P_{-1}$ and $D T F_{-1}$, expressing them in the functional forms with the highest instrumental power.

The best-fitting estimated models are represented by equations (9) and (10).

$$
\begin{gathered}
\text { RM4 : }\left\{\begin{array}{l}
\log (\text { indpago })=\gamma_{1} D C A T P R O 1+\gamma_{2} \text { bids }+u \\
\text { bids }=\lambda_{1} D C A T P R O 1+\lambda_{2} G D P_{-1}+\lambda_{3}\left(G D P_{-1}\right) *\left(D T F_{-1}\right)+v
\end{array}\right. \\
\text { RM5: }\left\{\begin{array}{l}
\log (\text { indpago })=\gamma_{1}^{\prime} D C A T P R O 1+\gamma_{2}^{\prime} \log (\text { bids })+u^{\prime} \\
\log (\text { bids })=\lambda_{1}^{\prime} D C A T P R O 1+\lambda_{2}^{\prime} \log \left(G D P_{-1}\right)+\lambda_{3}^{\prime} \log \left(D T F_{-1}\right)+v^{\prime}
\end{array}\right.
\end{gathered}
$$

Both estimation methods, 2SLS and GMM, provide the same coefficients, which is consistent with the linear form of the models. The instrumented coefficients for bids in model RM4 and $\log$ (bids) in model RM5 are negative as it was the case with the estimation of the models without instrumentation. Yet, the values are higher (less negative). In the model with bids in linear form, the variation with regards to model RM3v2 in Table 3 is of about 5\%, but in the model with bids in log form, the change is close to $20 \%$ indicating that there is indeed endogeneity of this variable in the model.

We conduct specific tests for the diagnosis of the instrumental models.

The first-stage F-statistic test provides evidence against the null hypothesis that the instruments both for model RM4 and RM5 are weak and, hence, we conclude that they are valid.

An overidentification robust score test indicates that adding $D T F_{-1}$ as a second instrument (in the adequate functional form) provides additional instrumental value in both models.

Finally, Hausman's endogeneity test does not allow rejecting the null hypothesis that using OLS to estimate the model RM3v2 yields consistent results. Thus, there is no significant evidence against considering bids exogenous in this model, and we prefer RM3v2 to instrumented model RM4. Reversely, Hausman's test applied to model RM5 shows evidence against the null hypothesis that $\log ($ bids $)$ is exogenous 
in model RM3v3 with a 99\% of confidence. We must therefore use the instrumented coefficient of this variable estimated in model RM5 for inference purposes.

As a final test, we replace $G D P_{-1}$ by $E X P O R T S_{-1}$ in our instrumental models to verify the robustness of the instrumented values.

$$
\begin{aligned}
& R M 4 v 2:\left\{\begin{array}{l}
\log (\text { indpago })=\gamma_{1} \text { DCATPRO } 1+\gamma_{2} \text { bids }+u \\
\text { bids }=\beta_{1} \text { DCATPRO } 1+\beta_{2} \text { EXPORTS }_{-1}+\beta_{3}\left(\text { EXPORTS }_{-1}\right) *\left(\text { DTF }_{-1}\right)+w
\end{array}\right. \\
& R M 5 v 2:\left\{\begin{array}{l}
\log (\text { indpago })=\gamma_{1}^{\prime} D C A T P R O 1+\gamma_{2}^{\prime} \log (\text { bids })+u^{\prime} \\
\log (\text { bids })=\beta_{1}^{\prime} D C A T P R O 1+\beta_{2}^{\prime} \log \left(\text { EXPORTS }_{-1}\right)+\beta_{3}^{\prime} \log \left(D_{T} F_{-1}\right)+w^{\prime}
\end{array}\right.
\end{aligned}
$$

The estimation of RM4v2 confirms that the variable bids in model RM3v2 does not show substantial endogeneity.

The estimation of RM5v2 yields coefficients that take basically the same values obtained in the estimation of RM5. They are displayed in Table 4. This confirms the endogeneity of bids in model RM3v3 and the robustness of the instrumental estimation.

\subsection{Discussion of selected empirical models}

We discuss in this section the specification of the selected empirical models:

- Flexible non-linear model

indpago $=1.151-0.154 D C A T P R O 1-0.132 B_{I D S_{2}}-0.166 B I D S_{3}-0.192 B I D S_{4}-$

$-0.277 B I D S_{5}-0.236 B I D S_{6}-0.242 B I D S_{7}-0.409 B I D S_{8}-0.209 B I D S_{9}-0.205 B I D S_{10}+v$

This flexible non-linear model points at a limit to the price competition effect as from eight bidders. This would be the typical bidding behavior of an auction environment satisfying the bidders' common value paradigm, where bidders try to avoid the winner's curse. This result is consistent with the discussions in previous works using a similar model, like (Brannman 1987).

- Semi-elasticity model.

$$
\log (\text { indpago })=-0.172 \text { DCATPRO } 1-0.027 \text { bids }+u
$$

This semi-elasticity model provides a semi-elasticity of -0.027 for non-furniture goods. The same model applied exclusively to furniture goods yields a semi-elasticity of -0.098 for this category of products. The weighted average is -0.031 . This result is comparable to that in (Onur and Özcam 2012), who obtain an average semi-elasticity of -0.039 with a similar model for an unrestricted sample of all kind of procurement auctions in Turkey. The lower elasticity in absolute value in our work may correspond to a higher proportion of technological products in Europe Aid auction environment. 
Table 4 Endogeneity correcting models for variable $\log ($ bids) in RM3v3. Linear approximation 2SLS and GMM estimation methods

\begin{tabular}{|c|c|c|c|c|}
\hline & \multirow{2}{*}{\multicolumn{2}{|c|}{$\begin{array}{l}\text { Dependent Variable: } \log (\text { indpago }) \\
\text { Instruments: } \log \left(G D P_{-1}\right) \\
\log \left(D T F_{-1}\right)\end{array}$}} & \multirow{2}{*}{\multicolumn{2}{|c|}{$\begin{array}{l}\text { Dependent Variable: } \log (\text { indpago }) \\
\text { Instruments: } \log \left(\text { EXPORTS }_{-1}\right) \\
\left.\log _{\left(D_{T}\right.}\right)\end{array}$}} \\
\hline & & & & \\
\hline & RM5(2SLS) & RM5(GMM) & RM5v2(2SLS) & RM5v2(GMM) \\
\hline DCATPRO1 & $\begin{array}{l}-0.1787^{*} \\
(0.1045)\end{array}$ & $\begin{array}{l}-0.1787^{* *} \\
(0.0896)\end{array}$ & $\begin{array}{l}-0.1789^{*} \\
(0.1045)\end{array}$ & $\begin{array}{l}-0.1789^{* *} \\
(0.0896)\end{array}$ \\
\hline $\log ($ bids $)$ & $\begin{array}{l}-0.0763^{* * *} \\
(0.0186)\end{array}$ & $\begin{array}{l}-0.0763^{* * *} \\
(0.0187)\end{array}$ & $\begin{array}{l}-0.0761^{* * *} \\
(0.0186)\end{array}$ & $\begin{array}{l}-0.0761^{* * *} \\
(0.0187)\end{array}$ \\
\hline Observations & 370 & 370 & 370 & 370 \\
\hline $\mathrm{R}^{2}$ & 0.097 & & 0.097 & \\
\hline Adjusted $\mathrm{R}^{2}$ & 0.092 & & 0.092 & \\
\hline F statistic $(\mathrm{df}=2 ; 368)$ & $11.20^{* * *}$ & & $11.10^{* * *}$ & \\
\hline
\end{tabular}

${ }^{*} \mathrm{p}<0.1 ;{ }^{* *} \mathrm{p}<0.05 ;{ }^{* * *} \mathrm{p}<0.01$

2SLS with robust estimations HC0; GMM in two steps with quadratic spectral kernel for HAC

- Elasticity model (instrumented)

$$
\log (\text { indpago })=-0.179 D C A T P R O 1-0.076 \log (\text { bids })+\epsilon
$$

The elasticity model is the best-fitting model according to criteria of statistic consistency. In this model, the competition effects would cease quickly with the entry of new bidders. The bidders' value would not be purely private. A certain level of affiliation would be expected. Once controlled for endogeneity, the model provides an elasticity of -0.08 for non-furniture goods. The same model applied exclusively to furniture goods yields an elasticity of -0.28 . The weighted average is close to -0.10 . This result is comparable to (Iimi 2006) who obtains an average elasticity of -0.2 in a model for an international sample of ODA auctions with high-value contracts over 7 EUR million, under simplifying IPVP assumptions. The lower elasticity in absolute value in our work may correspond to a higher proportion of technological products and to the absence of potential highvalue contract sample selection bias.

\subsection{Graphical representation of the determinant empirical models}

Figure 2 represents graphically the three determinant models in our study. The depicted values are the predictions conditioned to the entire values of the number of bidders between 2 and 10 and to the value 0 of the variable DCATPROI representing furniture goods. For models (14) and (15) we use the unbiased predictor of the level form for the dependent variable indpago. We calculate the exponential transformation from its logarithmic form as described in (Wooldridge 2012). We also 


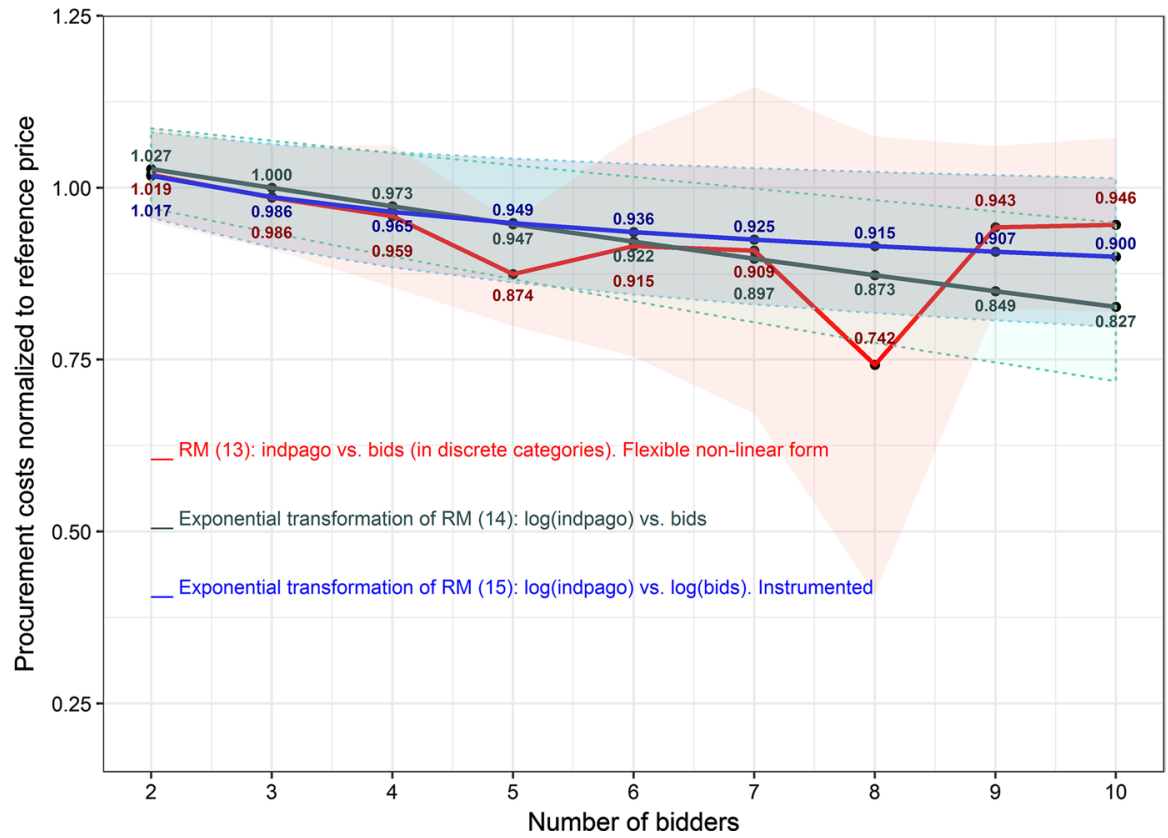

Fig. 2 Representation of the best-fitting models to determine the influence of competition on procurement cost. The figure shows normalized procurement costs predictors with their confidence bands for each number of bidders, excluding tenders for furniture goods

show the $95 \%$ confidence bands calculated with heteroskedasticity-robust standard errors.

\section{Conclusions}

We show evidence in our paper of the positive effect of increased competition on procurement cost savings for Europe Aid supply tenders funded with the Pre-accession (IPA) and Neighbourhood (ENI) instruments.

To conduct our research, we faced the absence of public databases. We built and curated a dataset from the official tenders published by Europe Aid. This dataset provides an added-value to our work.

The tenders in our study are called by the beneficiary countries of the IPA and ENI instruments. They are open to international bidders. The tendered lots include different products. The most frequent ones are technological and industrial equipment. Vehicles, medical materials and furniture complete this market.

Generally, the tenders require a participation guarantee to enter the bidding procedure. We define homogeneously a reference price for the supply tenders that require this guarantee. The amount of the guarantee signals publicly a high and a low price thresholds based on the contracting authority's engineered value of the lot. 
We calculate the reference price across tenders using the symmetric central value between the thresholds.

We identify the procurement cost with the winning bid and we normalize this cost to the calculated reference price. The normalized procurement cost is directly related with the procurement cost savings rate.

We estimate three consistent empirical models with a non-linear relationship between the procurement cost and the number of bidders, controlling for different features of the market. The results of our three models converge up to four bidders and diverge as from eight.

We do not find significant differences between the competition effects originating from tenders funded with IPA and ENI instruments. However, the category of furniture goods shows a more competitive behavior than the rest of the tendered products. This effect is reasonable in economic terms because furniture goods would not require very sophisticated production processes and could be furnished by several local providers.

We obtain an elasticity, a semi-elasticity and an individual price-effect for each number of bidders with our models. Our best-fitting model provides an elasticity close to -0.08 for all categories of non-furniture goods, once corrected from endogeneity. Considering furniture goods, the average elasticity is close to -0.1 . Our results are compatible with those from previous studies in similar public procurement environments.

The average number of bidders in our sample is three, including also the unsuccessful procedures. This figure is significantly below the critical value of eight bidders. Hence, we estimate with robustness the average savings rate, which is lower than $1.5 \%$ regarding the reference price for all categories of products, excluding furniture goods. This average savings rate indicates that measures promoting competition in Europe Aid supply tenders would achieve more significant savings, opening room for political action in this field. For instance, doubling the average number of bidders to six would achieve a savings rate in the range of $6.5 \%$ to $8.5 \%$, regardless of the model we use.

Referring savings to the unknown reserve price of the contracting authority would yield a higher value because, by construction, our reference price is strictly lower than the maximum reserve price in an approximate factor of 1.5. The estimated average savings rate referred to this extreme bound yields an approximate value of $35 \%$. However, it is reasonable to think that the contracting authority does not use the extreme bound when building her reserve price to avoid disclosing it.

Higher procurement cost savings with the promotion of competition in the tendering procedures would contribute directly to decrease the level of the external debt of beneficiary countries associated to other funding mechanisms and a more efficient use of fiscal resources of European donors. In addition, measures promoting competition would contribute to other objectives of ODA, like the further development of local markets and improved governance in beneficiary countries.

Other related areas of research include the extension to other Europe Aid beneficiary countries and other tender typologies like those of works and services, which would complement the characterization of Europe Aid procurement auction environment. 
Supplementary Information The online version contains supplementary material available at https://doi. org/10.1007/s10663-021-09518-5.

Funding Open Access funding provided thanks to the CRUE-CSIC agreement with Springer Nature.

Open Access This article is licensed under a Creative Commons Attribution 4.0 International License, which permits use, sharing, adaptation, distribution and reproduction in any medium or format, as long as you give appropriate credit to the original author(s) and the source, provide a link to the Creative Commons licence, and indicate if changes were made. The images or other third party material in this article are included in the article's Creative Commons licence, unless indicated otherwise in a credit line to the material. If material is not included in the article's Creative Commons licence and your intended use is not permitted by statutory regulation or exceeds the permitted use, you will need to obtain permission directly from the copyright holder. To view a copy of this licence, visit http://creativecommons.org/licen ses/by/4.0/.

\section{References}

Armantier O, Sbaï E (2006) Estimation and comparison of treasury auction formats when bidders are asymmetric. J Appl Econometrics 21(6):745-779

Bajari P (2001) Comparing competition and collusion: a numerical approach. Econ Theory 18(1):187-205

Brannman L et al (1987) The price effects of increased competition in auction markets. Rev Econ Stat 69(1):24-32

Campo I et al (2003) Asymmetry in first-price auctions with affiliated private values. J Appl Econometrics 18(2):179-207

Chapela J et al (2019) Further econometric evidence on the extent and sources of cost savings in competitively tendered contracts. Empirical Econ 56(2):679-701

Davidson R, MacKinnon J (2003) Econometric Theory and Methods. Oxford University Press

DEVCO (2018) Procurement and grants for european union external actions: A practical guide. http://ec. europa.eu/europeaid/prag/

EC (2020a) The instrument for pre-accession assistance. https://ec.europa.eu/neighbourhood-enlar gement/sites/near/files/ipa-factsheet-2020.pdf

EC (2020b) The neighbourhood, development and international cooperation instrument. https://ec. europa.eu/international-partnerships/system/files/factsheet-mff-multiannual-financial-frameworkv08-clean_0.pdf

Flambard V, Perrigne I (2006) Asymmetry in procurement auctions : Evidence from snow removal contracts. Econ J 116(514):1014-1036

Hendricks K, Porter R (1992) Joint bidding in federal ocs auctions. Am Econ Rev 82(2):506-511

Iimi A (2006) Auction reforms for effective official development assistance. Rev Ind Org 28(2):109-128

Milgrom P, Weber R (1982) The value of information in a sealed-bid auction. J Math Econ 10(1):105-114

OECD (2020) Aid by dac members increases in 2019 with more aid to the poorest countries. https:// www.oecd.org/dac/financing-sustainable-development/development-finance-data/ODA-2019-detai led-summary.pdf

Onur I, Özcam R (2012) Public procurement auctions and competition in Turkey. Rev Ind Org 40(3):207-223

Paarsch H (1992) Deciding between the common and private value paradigms in empirical models of auctions. J Econmet 51(1-2):191-215

Rezende L (2008) Econometrics of auctions by least squares. J Appl Econometrics 23(7):925-948

Tsanana P, Katrakilidis C (2014) Do Balkan economies catch up with EU? New evidence from panel unit root analysis. Empirica 41(4):641-662

Wooldridge JM (2012) Introductory Econometrics: A Modern Approach. South-Western

Publisher's Note Springer Nature remains neutral with regard to jurisdictional claims in published maps and institutional affiliations. 